\title{
BRCA1-mutated and basal-like breast cancers have similar aCGH profiles and a high incidence of protein truncating TP53 mutations
}

Henne Holstege ${ }^{1}$, Hugo M Horlings ${ }^{2,5}$, Arno Velds ${ }^{3}$, Anita Langerød ${ }^{4}$, Anne-Lise Børresen-Dale ${ }^{4}$, Marc J van de Vijver ${ }^{5}$, Petra M Nederlof ${ }^{2}$, Jos Jonkers ${ }^{1 *}$

\begin{abstract}
Background: Basal-like breast cancers (BLBC) are aggressive breast cancers for which, so far, no targeted therapy is available because they typically lack expression of hormone receptors and HER2. Phenotypic features of BLBCs, such as clinical presentation and early age of onset, resemble those of breast tumors from BRCA1-mutation carriers. The genomic instability of BRCA1-mutated tumors can be effectively targeted with DNA-damaging agents and poly-(ADP-ribose) polymerase 1 (PARP1) inhibitors. Molecular similarities between BLBCs and BRCA1-mutated tumors may therefore provide predictive markers for therapeutic response of BLBCs.

Methods: There are several known molecular features characteristic for BRCA1-mutated breast tumors: 1) increased numbers of genomic aberrations, 2) a distinct pattern of genomic aberrations, 3) a high frequency of TP53 mutations and 4) a high incidence of complex, protein-truncating TP53 mutations. We compared the frequency of TP53 mutations and the pattern and amount of genomic aberrations between BRCA1-mutated breast tumors, BLBCs and luminal breast tumors by TP53 gene sequencing and array-based comparative genomics hybridization (aCGH) analysis.
\end{abstract}

Results: We found that the high incidence of protein truncating TP53 mutations and the pattern and amount of genomic aberrations specific for BRCA1-mutated breast tumors are also characteristic for BLBCs and different from luminal breast tumors.

Conclusions: Complex, protein truncating TP53 mutations in BRCA1-mutated tumors may be a direct consequence of genomic instability caused by BRCA1 loss, therefore, the presence of these types of TP53 mutations in sporadic BLBCs might be a hallmark of BRCAness and a potential biomarker for sensitivity to PARP inhibition. Also, our data suggest that a small subset of genomic regions may be used to identify BRCA1-like BLBCs. BLBCs share molecular features that were previously found to be specific for BRCA1-mutated breast tumors. These features might be useful for the identification of tumors with increased sensitivity to (high-dose or dose-dense) alkylating agents and PARP inhibitors.

\section{Background}

Lobules and ducts within the normal human breast are lined with a double layer of epithelial cells: an inner layer of luminal cells and an outer layer of basal/myoepithelial cells that are in direct contact with the basement membrane. Transformation of different mammary

\footnotetext{
* Correspondence: j.jonkers@nki.nl

'Division of Molecular Biology, Netherlands Cancer Institute, Plesmanlaan

121, 1066 CX Amsterdam, The Netherlands

Full list of author information is available at the end of the article
}

epithelial cells results in considerable heterogeneity in breast cancer subtypes, giving rise to differences in clinical presentation, histology and response to therapy [1]. Gene expression profiling has identified five molecular breast tumor subtypes: luminal A, luminal B, normal breast-like, human epidermal growth factor 2 (HER2/ ERBB2) positive, and basal-like [2,3]. In the clinic however, only immunohistochemistry data for estrogen receptor (ER), progesterone receptor (PR) and HER2 status are used to guide treatment choice [4]. 
Approximately $\sim 70-80 \%$ of all breast tumors are hormone receptor positive [5] and therefore sensitive to adjuvant endocrine therapy [6]. These tumors classify mostly as luminal A/B breast tumors [3]. The addition of trastuzumab to adjuvant chemotherapy considerably improved the outcome of HER2-positive breast tumors [7]. However, approximately $10-20 \%$ of all breast tumors do not express hormone receptors or HER2, and are therefore insensitive to endocrine or trastuzumab treatment. Currently, the only treatment available for these triple-negative breast cancers (TNBCs) is cytotoxic chemotherapy [8].

The TNBC group as defined by immunohistochemical staining consists for approximately $80 \%$ of basal-like breast cancers (BLBCs) as defined by gene expression profiling [9]. BLBCs express luminal (CK19 and CK18) as well as basal cytokeratins (CK5/6, CK17 and CK14), suggesting that these tumors originate from an undifferentiated, dual-lineage stem/progenitor cell type. Furthermore, the TP53 gene is often mutated in BLBCs [10], and the gene expression profiles of TP53-mutated breast tumors show strong association with the BLBC subgroup [11]. Consequently, BLBCs are aggressive tumors with an expansive growth pattern (pushing margins), a high proliferation rate, high relapse rates and poor survival. Moreover, BLBCs occur more frequently in premenopausal women than in postmenopausal women and are often difficult to detect by mammography or ultrasound [9].

Although TNBC/BLBC has a relatively poor prognosis in the first five years after diagnosis, approximately $60 \%$ of patients - even without adjuvant chemotherapy - do not relapse, and after $\sim 8$ years of follow up have a high chance of being cured (reviewed in [9]). This indicates that within the TNBC/BLBC tumor group there is considerable heterogeneity in tumor behavior. At present however, all TNBC/BLBC patients are treated with cytotoxic adjuvant chemotherapy because there are no clinically useful prognostic and predictive markers to identify patients with aggressive, chemotherapy-sensitive TNBC/BLBC, leading to unnecessary exposure to chemotherapy of a substantial number of patients [8]. In recent years it is becoming clear that phenotypic features of TNBC/BLBC may also apply to the majority of hereditary BRCA1-mutated breast tumors [12,13]. Since BRCA1 function is required for homology-directed repair of DNA double-strand breaks (DSBs), BRCA1mutated tumors and BRCA1-like BLBCs are predicted to be sensitive to DSB inducing therapy [14]. Indeed, breast tumors from BRCA1-mutation carriers are sensitive to inhibition of DNA single-strand break (SSB) repair by poly(ADP-ribose) polymerase (PARP) inhibitors [15] and to chemotherapy that causes DSBs, such as platinum drugs, alkylating agents and topoisomerase I poisons [16,17]. It will therefore be important to identify features of sporadic BLBCs [14] that may be useful as predictive biomarkers for response to DSB-inducing chemotherapy or PARP inhibitors. Known molecular features characteristic for BRCA1-mutated breast tumors are 1) a high degree of genomic instability due to homologous recombination (HR) deficiency [18], 2) a distinct pattern of genomic aberrations [19-22] 3) a high frequency of TP53 mutations and 4) a high incidence of complex, protein-truncating TP53 mutations $[10,23]$. In this study, we determined to what extent these molecular characteristics of $B R C A 1$-mutated tumors are present in BLBCs.

\section{Methods}

\section{Breast tumor groups}

To compare molecular characteristics of BRCA1mutated tumors with BLBCs, we used data from two published tumor sets from the Netherlands Cancer Institute that were sequenced for TP53 and for which aCGH data was generated. The first dataset contains 27 BRCA1-mutated breast tumors and 17 luminal breast tumors (defined by expression profiling) that were previously described by Joosse et al [24]. The luminal tumors from this study were designated luminal-J: J for Joosse. The second dataset from Horlings et al., [25] contained 21 non-hereditary BLBCs and 31 luminal breast tumors that were part of a series of 295 breast tumor specimens [26] which were assigned to breast cancer subgroups according tot their gene expression profiles [2,3]. For privacy reasons $B R C A 1$ mutation status was not verified in the BLBCs, however, these patients did not have a family history of breast cancer. Luminal tumors from this study were labeled luminal- $\mathrm{H}, \mathrm{H}$ for Horlings. Six luminal breast tumors were used in both the Joosse study and the Horlings study. TP53 mutation, ER/PR/HER2, CK56 staining pattern and age at diagnosis of all tumors are shown in Table 1.

\section{TP53 mutation analyses}

For 21 BRCA1-mutated tumors, and 13 luminal-J tumors exons 2-9 of TP53 were previously sequenced [23]. The abundance of the aberrant base was estimated from the sequence chromatogram from both the forward and reverse sequencing runs. When comparing mutation types found in the tumor groups, the influence of tumor heterogeneity was minimized by only including TP53 mutations that had an estimated abundance of $>25 \%$ in the tumor DNA [23].

For all BLBC and luminal-H tumors TP53 exons 2-11 (including $+/-30$ bp outside each exon) were sequenced using $A B 3730$ DNA Analyzer (reference sequence NM_000546). 
Table 1 Tumor characteristics of BRCA1-related, Luminal-J, basal-like and Luminal-H breast tumors

\begin{tabular}{|c|c|c|c|c|c|c|c|c|c|c|}
\hline NKI ID & $\begin{array}{l}\text { deleterious TP53 } \\
\text { mutation by prediction }\end{array}$ & $\begin{array}{c}\text { complex/ } \\
\text { truncatingTP53 } \\
\text { mutation }\end{array}$ & $\begin{array}{l}\text { hotspot } \\
\text { mutation }\end{array}$ & $\begin{array}{l}\text { TP53 } \\
\text { IHC }\end{array}$ & $\begin{array}{l}\text { ER } \\
\text { IHC }\end{array}$ & $\begin{array}{l}\mathrm{PR} \\
\text { IHC }\end{array}$ & $\begin{array}{l}\text { HER2 } \\
\text { IHC }\end{array}$ & $\begin{array}{l}\text { CK5/ } \\
6 \mathrm{IHC}\end{array}$ & $\begin{array}{l}\text { breast cancer subtype/ } \\
\text { BRCA1 mutation }\end{array}$ & $\begin{array}{c}\text { Age at } \\
\text { diagnosis }\end{array}$ \\
\hline \multicolumn{11}{|c|}{ BRCA1-mutated breast tumors } \\
\hline B107 & G266E & 0 & 1 & 0 & 0 & 0 & 0 & NA & c.1319delT & 41 \\
\hline B109 & R213X, H214Y & 1 & 1 & 0 & 0 & 0 & 0 & NA & c.IVS21-36del510 & 30 \\
\hline B116 & Y163C & 0 & 1 & 1 & 0 & 0 & 0 & NA & c.185delAG & 49 \\
\hline B118 & NA & NA & NA & 0 & 0 & 0 & 0 & NA & c.4416_4417delTTinsG & 34 \\
\hline B119 & NA & NA & NA & 0 & 0 & 0 & 0 & NA & c.4416_4417delTTinsG & 34 \\
\hline B122 & 239 inst & 1 & 0 & 0 & 0 & 0 & 0 & NA & c. $4446 C>T$ & 45 \\
\hline B124 & NA & NA & NA & 1 & 0 & 0 & 0 & NA & c.3875del4 & 61 \\
\hline B125 & NA & NA & NA & 0 & 0 & 0 & 0 & NA & c.2804delAA & 35 \\
\hline B126 & del 255 & 1 & 0 & 1 & 0 & 0 & 0 & NA & c.IVS21-36del510 & 40 \\
\hline B127 & T551 & 0 & 0 & 1 & 0 & 0 & 0 & NA & c.5382insC & 39 \\
\hline B135 & wild type & 0 & 0 & 1 & 0 & 0 & 0 & NA & c.2312del5 & 41 \\
\hline B137 & 224 splice G > A & 1 & 0 & 0 & 0 & 0 & 0 & NA & c.IVS12-1632del3835 & 32 \\
\hline B141 & wild type & 0 & 0 & 0 & 0 & 0 & 0 & NA & c.IVS21-36del510 & 39 \\
\hline B145 & 110 delC, Q100X & 1 & 0 & 0 & 0 & 0 & 0 & NA & c.185delAG & 33 \\
\hline B146 & 145 delG, Q104X, P98S & 1 & 0 & 0 & 0 & 0 & 0 & NA & c.185delAG & 33 \\
\hline B149 & $\mathrm{R} 273 \mathrm{H}$ & 0 & 1 & 1 & 0 & 0 & 0 & NA & c.IVS20+1G > A & 31 \\
\hline B150 & V216 M, P223 S, R290C & 0 & 1 & 0 & 0 & 0 & 0 & NA & c.IVS21-36del510 & 41 \\
\hline B152 & $\mathrm{R} 175 \mathrm{H}$ & 0 & 1 & 1 & 0 & 0 & 0 & NA & c.IVS13+4123ins6081 & 47 \\
\hline B153 & del $155-156$ & 1 & 0 & 1 & 0 & 0 & 0 & NA & c.185delAG & 48 \\
\hline B156 & R248W, R280K, V218I & 0 & 1 & 1 & 0 & 0 & 0 & NA & c.5382insC & 47 \\
\hline B158 & R282G, E326K & 0 & 1 & 1 & 0 & 0 & 0 & NA & c.IVS21-36del510 & 27 \\
\hline B160 & 167 insA & 1 & 0 & 0 & 0 & 0 & 0 & NA & c.IVS20+1G > A & 61 \\
\hline B161 & R213X, R282W, P151R & 1 & 1 & 1 & 0 & 0 & 0 & NA & c.IVS13+4123ins6081 & 30 \\
\hline B162 & NA & NA & NA & 0 & 0 & 0 & 0 & NA & c.IVS20+1G > A & 27 \\
\hline B164 & 258 delG & 1 & 0 & 0 & 0 & 0 & 0 & NA & c.del exons 1A-7 & 31 \\
\hline B165 & NA & NA & NA & 1 & 0 & 0 & 0 & NA & c.IVS12-1632del3835 & 33 \\
\hline B171 & $\mathrm{R} 306 \mathrm{X}$ & 1 & 0 & 0 & 0 & 0 & 1 & NA & c.IVS2-9C > G & 33 \\
\hline \multicolumn{11}{|c|}{ Luminal-J breast tumors } \\
\hline C002 & R248W, R110C, T55I & 0 & 1 & 0 & 0 & 0 & 1 & 0 & Luminal A & 45 \\
\hline $\mathrm{C} 010$ & NA & NA & NA & 0 & 1 & 1 & 0 & 0 & Luminal A & 40 \\
\hline C017 & K305X & 1 & 0 & 0 & 1 & 1 & 0 & 0 & Luminal B & 36 \\
\hline $\mathrm{CO2O}$ & wild type & 0 & 0 & 1 & 0 & 0 & 0 & 1 & Luminal A & 34 \\
\hline C022 & NA & NA & NA & 0 & 1 & 0 & 0 & 0 & Luminal B & 51 \\
\hline C025 & P177L & 0 & 1 & 0 & 1 & 1 & 0 & 0 & Luminal A & 50 \\
\hline C027 & NA & NA & NA & 0 & 1 & 1 & 1 & 0 & Luminal A & 45 \\
\hline C028 & wild type & 0 & 0 & 0 & 1 & 1 & 0 & 0 & Luminal B & 41 \\
\hline C030 & wild type & 0 & 0 & 0 & 1 & 0 & 0 & 0 & Luminal B & 38 \\
\hline C034 & wild type & 0 & 0 & 0 & 1 & 1 & 0 & 0 & Luminal A & 47 \\
\hline C036 & wild type & 0 & 0 & 0 & 1 & 1 & 0 & 0 & Luminal A & 40 \\
\hline C037 & NA & NA & NA & 0 & 1 & 1 & 0 & 0 & Luminal B & 49 \\
\hline C042 & P190L & 0 & 0 & 0 & 1 & 1 & 0 & 0 & Luminal B & 42 \\
\hline C044 & wild type & 0 & 0 & 0 & 1 & 0 & 0 & 0 & Luminal B & 45 \\
\hline C052 & wild type & 0 & 0 & 0 & 1 & 1 & 0 & 0 & Luminal A & 45 \\
\hline C057 & P98L & 0 & 0 & 0 & 0 & 0 & 0 & 0 & Luminal B & 51 \\
\hline $\mathrm{CO60}$ & $\mathrm{H} 179 \mathrm{R}, \mathrm{T} 125 \mathrm{M}$ & 0 & 1 & 1 & 1 & 1 & 0 & 0 & Luminal B & 47 \\
\hline \multicolumn{11}{|c|}{ Basal-like breast tumors } \\
\hline 131 & 239_240delCA & 1 & 0 & 1 & 0 & 0 & 0 & 1 & Basal-like & 39 \\
\hline 135 & C242Y & 0 & 1 & 1 & 0 & 0 & 0 & 1 & Basal-like & 45 \\
\hline 164 & W53X & 1 & 0 & 0 & 0 & 0 & 0 & 1 & Basal-like & 50 \\
\hline
\end{tabular}


Table 1 Tumor characteristics of BRCA1-related, Luminal-J, basal-like and Luminal-H breast tumors (Continued)

\begin{tabular}{|c|c|c|c|c|c|c|c|c|c|c|}
\hline 184 & 183_184insC & 1 & 0 & 0 & 0 & 0 & 0 & 1 & Basal-like & 44 \\
\hline 215 & 110delC & 1 & 0 & 0 & 0 & 0 & 0 & 1 & Basal-like & 49 \\
\hline 228 & IVS5-2 A > C (splice) & 1 & 0 & 0 & 0 & 0 & 0 & 0 & Basal-like & 39 \\
\hline 230 & E221X & 1 & 0 & 0 & 0 & 0 & 1 & 0 & Basal-like & 28 \\
\hline 238 & V173M & 0 & 1 & 1 & 0 & 0 & 0 & 1 & Basal-like & 42 \\
\hline 241 & R196X & 1 & 0 & 0 & 0 & 0 & 0 & 1 & Basal-like & 41 \\
\hline 268 & L252P & 0 & 0 & 1 & 0 & 0 & 0 & 1 & Basal-like & 38 \\
\hline 269 & N131S & 0 & 0 & 0 & 0 & 1 & 0 & 1 & Basal-like & 38 \\
\hline 270 & 283insGC & 1 & 0 & 0 & 0 & 0 & 0 & 1 & Basal-like & 50 \\
\hline 307 & 218delGTG & 1 & 0 & 1 & 0 & 0 & 0 & 1 & Basal-like & 44 \\
\hline 324 & I195T & 0 & 1 & 1 & 0 & 0 & 0 & 1 & Basal-like & 46 \\
\hline 326 & 155_156del & 1 & 0 & 1 & 0 & 0 & 0 & 1 & Basal-like & 39 \\
\hline 330 & 201delT & 1 & 0 & 0 & 0 & 0 & 0 & 1 & Basal-like & 26 \\
\hline 332 & Q286K & 0 & 1 & 1 & 0 & 0 & 0 & 1 & Basal-like & 49 \\
\hline 335 & R248W & 0 & 1 & 1 & 0 & 0 & 0 & 1 & Basal-like & 48 \\
\hline 367 & wild type & 0 & 0 & 1 & 1 & 0 & 1 & 0 & Basal-like & 49 \\
\hline 377 & 255_256delTCA & 1 & 0 & 1 & 1 & 1 & 0 & 1 & Basal-like & 52 \\
\hline 398 & Y220C & 0 & 1 & 1 & 0 & 0 & 0 & 1 & Basal-like & 34 \\
\hline \multicolumn{11}{|c|}{ Luminal-H breast tumors } \\
\hline 6 & wild type & 0 & 0 & 0 & 1 & 1 & 0 & 0 & Luminal A & 49 \\
\hline 107 & Q317X & 1 & 0 & 0 & 1 & 1 & 0 & NA & Luminal B & 38 \\
\hline 110 & wild type & 0 & 0 & 0 & 1 & 1 & 0 & 0 & Luminal B & 51 \\
\hline 145 & R273C & 0 & 1 & 0 & 0 & 1 & 0 & 0 & Luminal B & 48 \\
\hline $\begin{array}{l}157 \\
(\mathrm{COO2}) \\
*\end{array}$ & R248W & 0 & 1 & 0 & 0 & 0 & 1 & 0 & Luminal A & 45 \\
\hline 166 & wild type & 0 & 0 & 0 & 1 & 0 & 0 & 0 & Luminal B & 43 \\
\hline 167 & wild type & 0 & 0 & 0 & 1 & 1 & 1 & 0 & Luminal A & 44 \\
\hline 176 & wild type & 0 & 0 & 0 & 0 & 1 & 0 & 0 & Luminal A & 46 \\
\hline 203 & wild type & 0 & 0 & 0 & 1 & 1 & 1 & 0 & Luminal A & 49 \\
\hline 205 & $\mathrm{~K} 132 \mathrm{R}$ & 0 & 1 & 0 & 1 & 1 & 0 & 1 & Luminal A & 50 \\
\hline 214 & wild type & 0 & 0 & 0 & 1 & 1 & 0 & 0 & Luminal A & 41 \\
\hline 220 & wild type & 0 & 0 & 0 & 1 & 1 & 0 & 0 & Luminal A & 42 \\
\hline 231 & wild type & 0 & 0 & 0 & 1 & 1 & NA & 0 & Luminal A & 43 \\
\hline $\begin{array}{l}240 \\
(\mathrm{C} 060) \\
*\end{array}$ & $\mathrm{H} 179 \mathrm{R}$ & 0 & 1 & 0 & 1 & 1 & 0 & 0 & Luminal B & 47 \\
\hline 295 & wild type & 0 & 0 & 0 & 1 & 1 & 0 & 0 & Luminal A & 48 \\
\hline 298 & wild type & 0 & 0 & 1 & 1 & 1 & 0 & 0 & Luminal A & 50 \\
\hline $\begin{array}{l}302 \\
(\mathrm{C} 034) \\
*\end{array}$ & wild type & 0 & 0 & 0 & 1 & 1 & 0 & 0 & Luminal A & 47 \\
\hline $\begin{array}{l}305 \\
(\mathrm{C} 036) \\
*\end{array}$ & wild type & 0 & 0 & 0 & 1 & 1 & 0 & 0 & Luminal A & 40 \\
\hline 312 & 205delT & 1 & 0 & 0 & 1 & 1 & 0 & 0 & Luminal B & 47 \\
\hline 318 & R110L, S127C & 0 & 1 & 0 & 1 & 1 & 0 & 0 & Luminal A & 37 \\
\hline $\begin{array}{l}322 \\
(\mathrm{CO} 44) \\
*\end{array}$ & wild type & 0 & 0 & 0 & 1 & 0 & 0 & 0 & Luminal B & 45 \\
\hline 329 & wild type & 0 & 0 & 0 & 1 & 1 & 0 & 0 & Luminal B & 49 \\
\hline 346 & wild type & 0 & 0 & 0 & 1 & 1 & 0 & 0 & Luminal A & 49 \\
\hline 354 & P177R & 0 & 1 & 1 & 1 & 1 & 0 & 1 & Luminal A & 47 \\
\hline 356 & wild type & 0 & 0 & 0 & 1 & 1 & 0 & 0 & Luminal A & 49 \\
\hline 361 & wild type & 0 & 0 & 0 & 1 & 1 & 0 & 0 & Luminal A & 42 \\
\hline
\end{tabular}


Table 1 Tumor characteristics of BRCA1-related, Luminal-J, basal-like and Luminal-H breast tumors (Continued)

\begin{tabular}{|c|c|c|c|c|c|c|c|c|c|c|}
\hline 371 & wild type & 0 & 0 & 1 & 1 & 0 & 0 & 0 & Luminal A & 51 \\
\hline 378 & wild type & 0 & 0 & 0 & 1 & 0 & 0 & 0 & Luminal B & 52 \\
\hline $\begin{array}{l}389 \\
(C 057) \\
*\end{array}$ & wild type & 0 & 0 & 0 & 1 & 0 & 0 & 0 & Luminal B & 51 \\
\hline 391 & wild type & 0 & 0 & 0 & 1 & 0 & 0 & 0 & Luminal A & 51 \\
\hline 393 & wild type & 0 & 0 & 0 & 1 & 1 & 0 & 0 & Luminal B & 51 \\
\hline
\end{tabular}

TP53 mutations Bold: predicted truncating TP53 mutation (frameshift, splice, nonsense and in-frame insertions or deletions), plain text: hotspot mutations according to Walker et al. Italics, missense TP53 mutations predicted deleterious by the SIFT or EffectGroup3 algorithms. Immunohistochemistry data for TP53, ER, PR, HER2 and CK5/6; BRCA1-mutation; tumor type as determined by expression profiling; age at diagnosis.

*The TP53 gene of the BRCA1-mutated, Luminal-J tumors were sequenced in a different laboratory than the BLBCs and the luminal-H tumors. Of the 6 overlapping tumors between Luminal- $\mathrm{H}$ and Luminal-J tumors a discrepancy occurs in 3 tumors: In luminal-H tumor 157 a R248W mutation is found and in corresponding Luminal-J tumor C002 an additional R110C and T55I mutations are found. In luminal-J tumor C057 a P98L mutation is found and corresponding luminal-H tumor 389 no mutations are found. In luminal-H tumor 240 a H179R mutation is detected and in corresponding luminal-J tumor C060 an additional T125 M mutation is found.

Frameshift, splice and nonsense mutations and inframe insertions/deletions are defined as "complex TP53 mutations". All missense mutations found in the BRCA1-mutated and luminal-J tumor groups were classified according to their predicted effect on p53 function as determined by the Sorting Intolerant from Tolerant algorithm SIFT; $[27,28]$, as used in the IARC TP53 database $[29,30]$. Because no matched normal/germ-line DNA was available, some benign germ-line variants may have been identified as deleterious somatic mutations by SIFT. All TP53 missense mutations found in the BLBC and luminal-H tumor groups were classified to be deleterious or non-deleterious according to their predicted effect on TP53 function using "EffectGroup3" [31] as used in the IARC TP53 database. The 29 most common hotspot mutations $(\mathrm{P}<0.001)$ identified by Walker and colleagues [32] are referred to as "hotpot mutations": K132, C135, P151, V157, R158, Y163, V173, R175, C176, H179, H193, Y205, Y220, Y234, M237, C238, S241, C242, G245, M246, R248, R249, G266, R273, P278, R280, D281, R282, and E285.

\section{Comparisons aCGH data derived from FFPE and fresh frozen tissue}

For aCGH procedures of the BRCA1-mutated and luminal-J tumor groups: see Joosse et al., 2009 [24]. For aCGH procedures of the BLBC and luminal-H tumor groups: see Horlings et al., [25]. For the aCGH analyses, a microarray platform containing 3,500 human BAC/ PAC clones covering the whole genome with an average spacing of $1 \mathrm{Mb}$ was used [33]. Although the $1 \mathrm{Mb}$ resolution of the $\mathrm{BAC}$ platform limits sensitivity for focal changes, the aCGH data is a sound representation of our tumor groups and can be used to find recurrent differences between tumor groups.

When comparing aCGH profiles of tumor DNA isolated from formalin-fixed paraffin-embedded (FFPE) tissue [24] and fresh-frozen tissue [25], we noticed that the log2-ratios obtained from the different DNA sources showed different distributions. From the six overlapping samples between the luminal- $\mathrm{H}$ and luminal-J tumor groups, as shown in Table 1 we saw that distribution of $\log 2$-ratios derived from FFPE samples was consistently wider than the log2-ratios derived from fresh frozen tissue (Additional File 1). Therefore, we transformed both the FFPE (i.e. all $\log 2$ ratios from BRCA1-mutated and luminal-J tumors taken together) and the fresh frozen datasets (i.e. all $\log 2$ ratios from BLBC and luminal-H tumors taken together) to have a mean of zero and a standard deviation of one before applying KC-SMART and comparative-KC-SMART. This enabled us to construct one luminal tumor group consisting of tumors from both the luminal- $\mathrm{H}$ and luminal-J tumor groups to compare the BRCA1-mutated and BLBC-data with. The six tumors that overlapped between the two groups were included only once and taken from the luminal-J tumor group.

\section{KC-SMART and comparative-KC-SMART analysis KC-SMART}

(Kernel Convolution - a Statistical Method for Aberrant Region detection) is a computational approach for statistical analysis of non-discretized aCGH data from multiple experiments, and determines which regions are significantly gained or lost relative to randomized data $(\mathrm{P}<0.05)$ [34]. We used KC-SMART to smooth the raw $\log 2$-ratios by generating a Kernel Smoothed Estimate (KSE) curves for gains (KSE gains) and losses (KSElosses) separately across a group of tumors.

\section{Comparative-KC-SMART}

[35] detects genomic regions that have a differential aCGH signal between two tumor groups. The comparative-KC-SMART algorithm smoothes raw log2-ratio data from each individual tumor profile by placing Gaussian kernel functions with the height of the log2ratio at the genomic midposition of each probe (without 
separating gains and losses, as done for KC-SMART). For each tumor, an aggregated profile is determined by convolution of locally weighted kernel functions. For each genomic position, the KSE values from all tumors that belong to the two tumor groups in the comparison are used to calculate a signal to noise ratio (SNR). We determined a cut-off that defines significant SNR values by generating SNR data using 6000 class-label permutations and calculating the significance threshold corresponding with a False Discovery Rate (FDR) of 0.05 . The width of a kernel applied to each data point determines the extent of smoothing and the size of aberrations detected. Smoothing individual tumors with a kernel width of $20 \mathrm{Mb}$ resulted in aCGH profiles that recapitulated raw aCGH data well; therefore, we chose to use this kernel width for all comparisons. R-packages of KC-SMART and comparative-KC-SMART have been submitted to Bioconductor [36]. We used NCBI Build 36 ( $\mathrm{Hg} \mathrm{18)}$ for these analyses.

\section{Clustering analysis}

We used the MeV program [37] to cluster tumor aCGH data. Samples and genes are hierarchically clustered using pearson correlation and complete linkage with leaf ordening.

\section{Results}

\section{TP53 mutations in BRCA1-mutated, BLBC and luminal} breast cancers

We previously found that nearly all BRCA1-mutated breast tumors had deleterious TP53 mutations due to an increased frequency of truncating frameshift, splice, nonsense mutations and in-frame insertions and deletions [23]. BRCA1-mutated tumors and BLBCs are both basal like TNBCs, characteristics that are different from hormone receptor positive luminal breast tumors (Table 1). Therefore, we were motivated to compare TP53 mutation type and frequency found in non-hereditary BLBCs, in BRCA1-mutated tumors and in luminal breast tumors. TP53 mutation types and other tumor characteristics are listed in Table 1 . The TP53 gene from the BRCA1mutated/luminal-J tumors and the BLBC/luminal- $\mathrm{H}$ tumors were sequenced in different labs with slightly different methods (see Methods section). At the cost of reducing the power of this analysis we wanted to make sure we did not introduce a methodical bias in our comparisons, therefore, the TP53 mutation data for luminal-J and luminal-H tumors were not combined.

Similar to the $90 \%(19 / 21)$ of BRCA1-mutated tumors, 95\% (20/21) of the BLBCs harbored TP53 mutations, significantly more than the $46 \%(6 / 14)$ of the luminal-J and the $26 \%(8 / 31)$ of the luminal- $\mathrm{H}$ tumors $(\mathrm{p}=7 \times$ $10^{-3}$ and $\mathrm{p}=5 \times 10^{-7}$ respectively, two-tailed Fisher's Exact test), Figure 1 Additional File 2. We next
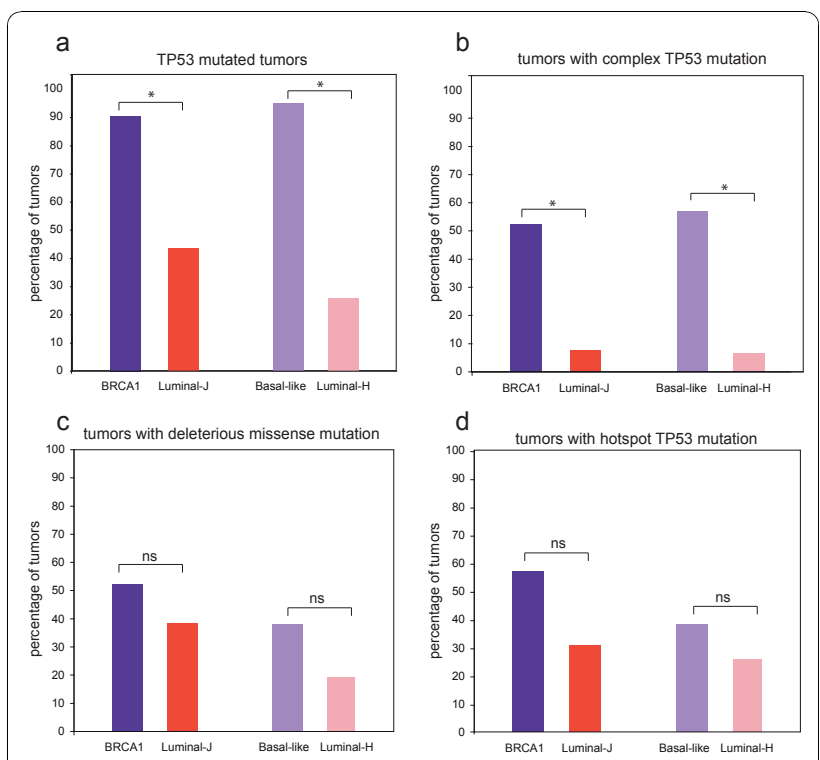

Figure 1 Analysis of TP53 mutations in BRCA1-mutated tumors and BLBCs. TP53 exons 2-9 were sequenced for 21/27 of the BRCA1-mutated tumors and for 13/21 of the luminal-J tumors. TP53 exons 2-11 were sequenced for all 21 BLBCs and 31 luminal-H tumors (see Table 1 for TP53 mutations see Additional File 1 for TP53 mutation frequencies). a. Amount of tumors with at least one TP53 mutation. b. Amount of tumors with at least one complex, predicted truncating TP53 mutation (frameshift, splice and nonsense mutations and in-frame insertions/deletions). c. Amount of tumors with at least one deleterious missense mutation. $\mathbf{d}$. the amount of tumors with at least one hotspot mutation as defined by Walker et al. Three BRCA1-mutated tumors have a complex/truncating TP53 mutation and also a deleterious missense mutation. ${ }^{*}$ Significant difference between groups ( $p<0.01$, determined with a Fisher's Exact Test), ns: no significant difference between groups.

compared TP53 mutation types from BRCA1-mutated tumors and non-hereditary BLBCs with luminal-H and luminal-J tumors. We found that $52 \%(11 / 21)$ of the BRCA1-mutated tumors and 57\% (12/21) of the BLBCs have complex/truncating TP53 mutations, which is significantly more than the $8 \%(1 / 13)$ and $7 \%(2 / 31)$ of the luminal-J and luminal- $\mathrm{H}$ tumors, respectively $(\mathrm{p}=1 \times$ $10^{-2}$ and $\mathrm{p}=8 \times 10^{-5}$ respectively; two-tailed Fisher's Exact test, Figure 1 Additional File 2), indicating that this feature is common in hereditary BRCA1-mutated breast tumors and non-hereditary BLBCs. Interestingly, the increase in deleterious missense or hotspot TP53 mutations in BRCA1-mutated or BLBCs $(8 / 21)$ their respective luminal tumor groups was not significant. Deleterious missense mutations: 11/21 BRCA1-mutated vs. 5/13 luminal-J, $\mathrm{p}=5 \times 10^{-1}$, and $8 / 21 \mathrm{BLBCs}$ vs. $6 / 31$ luminal-H tumors $\mathrm{p}=2 \times 10^{-1}$, two-tailed Fisher's Exact test). Hotspot mutations: 9/21 BRCA1-mutated vs. $3 / 13$ luminal-J, $\mathrm{p}=3 \times 10^{-1}$, and $6 / 21$ BLBCs vs. $6 / 31$ luminal-H tumors $\mathrm{p}=5 \times 10^{-1}$, two-tailed Fisher's Exact test). Together, these data suggest that the increase of 
TP53 mutations in the BRCA1-mutated tumors and $\mathrm{BLBCs}$ is primarily due to the increase in complex/truncating TP53 mutations.

\section{Comparison of aCGH profiles of BRCA1-mutated tumors, BLBCs and luminal breast cancers}

To identify DNA copy number aberrations (CNAs) that occur significantly more often in BRCA1-mutated breast tumors than in BLBCs, we analyzed their aCGH with comparative-KC-SMART, a computational method for detection of genomic regions that have a significantly different aCGH signal between two tumor groups [35]. However, the DNA samples used to acquire aCGH profiles for the BLBC and the BRCA1-mutated tumor groups were isolated from fresh frozen tissue and FFPE material respectively, resulting in differences in $\log 2$ ratio distribution of the aCGH profiles (Additional File $1)$. To account for this difference, we normalized the data as explained in the Methods section. We applied comparative-KC-SMART to the normalized aCGH data of the BRCA1-mutated tumor group and the BLBC group (Figure 2a). Comparative-KC-SMART detected small CNAs on chromosomes 5, 7, 8 and 14 that are significantly different between these tumor groups (for regions and cancer-related genes see Additional File 3). BRCA1-specific losses and BLBC-specific gains on chromosomes 5 and 7 flanked each other and seem to be dependent on each other. Interestingly, the BRCA1specific chromosome 7 loss encompasses EGFR. The BRCA1-specific gain on chromosome 14 peaks at the $\mathrm{T}$ cell receptor alpha $(T C R \alpha)$ locus and encompasses, among other cancer-related genes, poly(ADP-ribose) polymerase 2 (PARP2), and B-cell lymphoma 2 like 2 (BCL2L2). Whether any of the genes located within these CNAs promote survival of BRCA1-deficient cells remains to be established.

Next, we used comparative-KC-SMART to compared CNAs in the BRCA1-mutated tumors and BLBCs vs. the combined luminal tumors (Figure 2b-c). Differential gains and losses are shown in Additional File 4. We compared CNAs between Luminal-J and luminal-H tumors as a control for merging these tumor groups (Figure 2d): as expected, no differences between the two luminal groups were detected.

Gains on chromosomes $1 \mathrm{q}$ and $16 \mathrm{p}$, and the loss on chromosome $16 \mathrm{q}$ occur more often in the luminal tumors than in the basal-like/BRCA1-mutated tumors (Figure 2b-c, Table 2). The first chromosome 1q gain peaks at $177.31 \mathrm{Mb}$; the second 1q gain peaks at 202.65 Mb close to MDM4 (202.81 Mb). Similarly, the 16p gain peaks at $15.7 \mathrm{Mb}$. The chromosome $16 \mathrm{q}$ loss consists of two peaks: the first peak maps to $52.19 \mathrm{Mb}$, at the BRD7, CYLD, and RBL2/p130 genes. The second peak maps to $79.19 \mathrm{Mb}$, at one of the most active common fragile sites in the human genome, FRA16 D, associated with the WWOX gene $(77.24 \mathrm{Mb})$. Many of the luminal tumors show a co-occurrence of chromosome 1q gain and 16q loss (Additional File 5).

\section{Impact of TP53 mutation on luminal tumors}

Because BLBCs and BRCA1-mutated tumors are almost always TP53-mutated, we investigated whether TP53 mutations are associated with specific CNAs in luminal tumors. We stratified the 31 luminal- $\mathrm{H}$ tumors by their TP53 mutation status and used comparative-KCSMART to compare both tumor groups. Although no differences were detected between CNAs from 8 TP53mutated and 23 TP53 wild-type luminal breast tumors, quantitative differences in KC-SMART profiles can be observed, Figure 3. TP53-mutated tumors have more overall gains on chromosomes $3 q, 6 p, 20 q, 21 q$ and $22 q$ and losses on chromosomes 2q, 3p, 4p, 4q, 13q, 15q and $\mathrm{X}$. On the other hand, TP53 wild-type tumors have a higher incidence of chromosome 1q gain, and 16q loss. However, these data do not provide evidence for an altered profile of TP53-mutated luminal breast tumors, perhaps because the TP53-mutated tumor group is too small for robust statistical analysis.

\section{Analysis of genomic instability in BRCA1-mutated tumors and BLBCs}

To determine the amount of CNAs in the different tumor groups, we used KC-SMART to smooth individual aCGH profiles and counted the amount of CNAs exceeding a range of cutoffs for each tumor separately. We found that the median amount of CNAs of BRCA1mutated tumors was not different from the amount of CNAs found in BLBCs (Figure 4a). In contrast, we found that the median amount of CNAs is significantly greater in the BRCA1-mutated tumors compared with luminal breast tumors between KSE cutoffs 0.02 and 0.1 and between 0.24 and $0.74(\mathrm{P}<0.01$, two sided t-test Figure $4 \mathrm{~b})$. Similarly, the median amount of CNAs in the BLBCs was higher compared with luminal tumors for KSE cutoffs between 0.02 and 0.14 and between 0.28 and 0.96 (Figure 4c). We did not detect differences in the median amount of aberrations between luminal-J breast tumors and luminal-H except for KSE cutoffs 0.2 and 0.24 (Figure $4 \mathrm{~d}$ ).

\section{Overlapping gains and losses specific for BLBCs and BRCA1-mutated tumors}

We compared gains and losses specific for the BLBC/ $B R C A 1$-mutated tumor groups relative to the luminal tumor groups. The BLBC/BRCA1-mutated tumors harbored overlapping differential gains on chromosomes $1 \mathrm{p}$, 2 p, 3q, 6p, 6q, 7q, 8q, 10p, 12p, 13q and 19q and losses on chromosomes 3p, 4p, 5q, 10q, 12q, 14q and 15q. The 

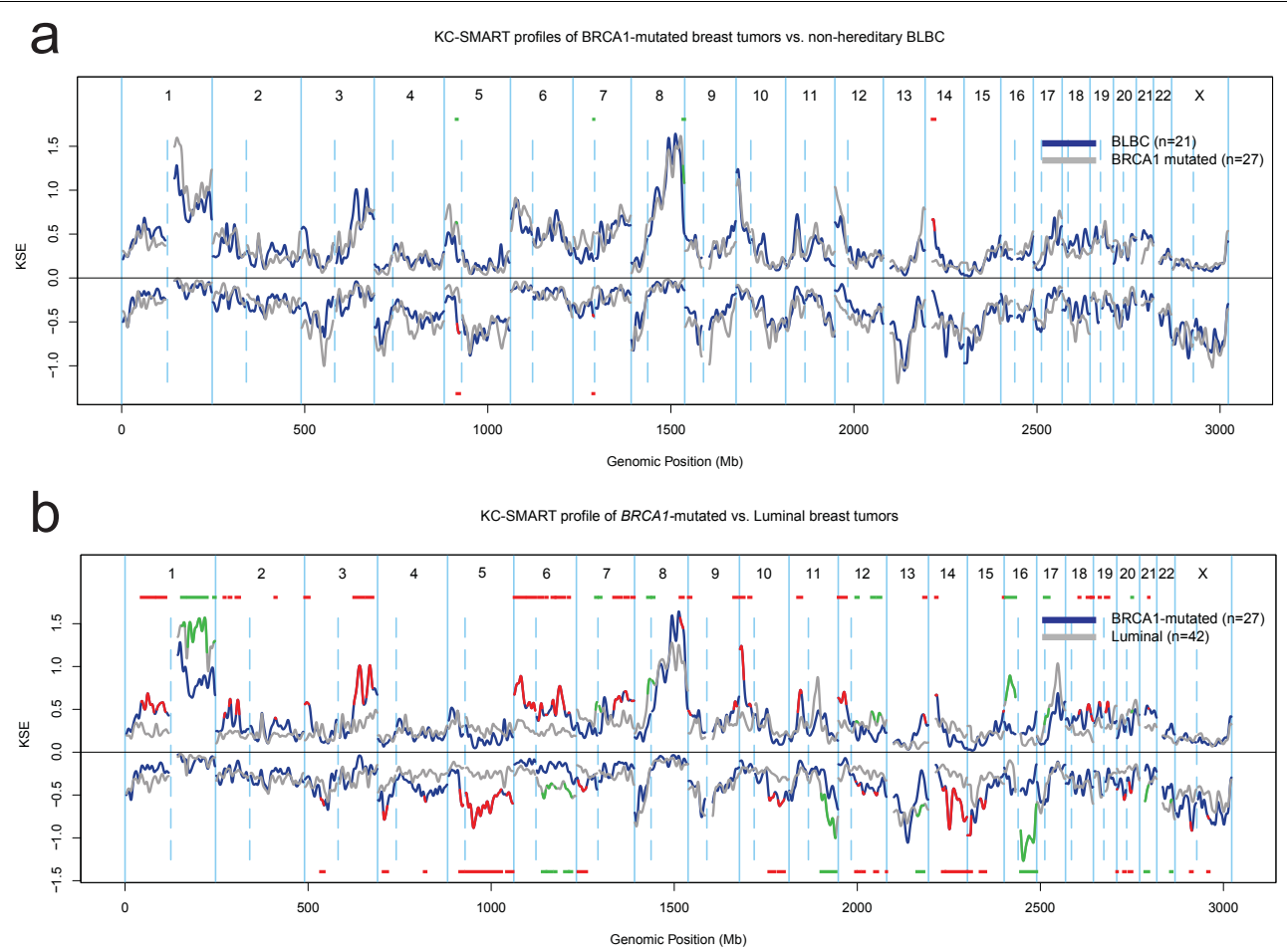

C KC-SMART profile of BLBC vs. Luminal breast tumors
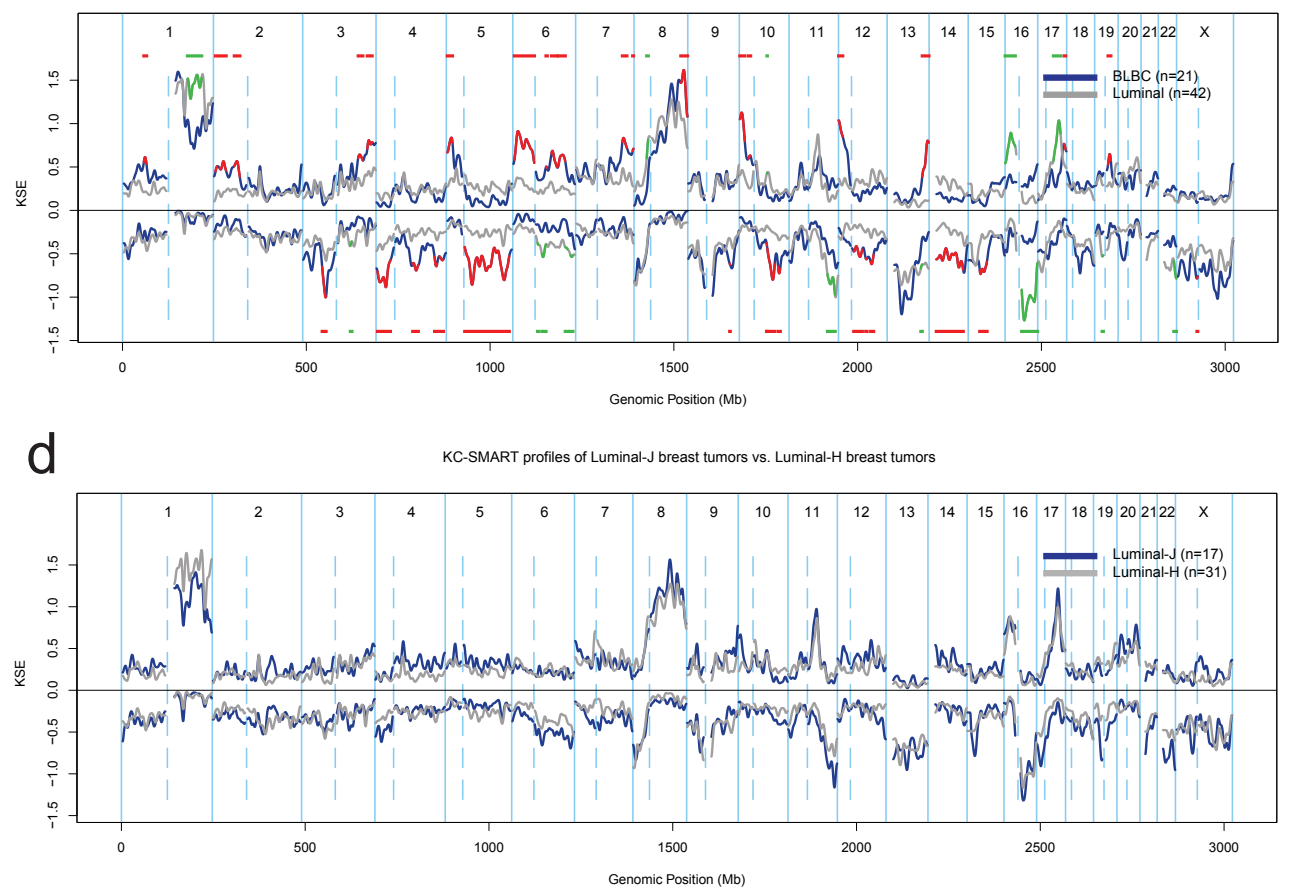

Figure 2 Comparative-KC-SMART analysis of aCGH data from BRCA1-mutated tumors and BLBCs. For each tumor group, comparative-KCSMART was applied to normalized aCGH data, which was scaled to have a mean of zero and a standard deviation of one. The KSE curves for each tumor group are shown for gains and losses separately. a: BRCA1-mutated breast tumors (blue) vs. BLBCs (gray). CNAs that occur more often in the BRCA1-mutated tumors vs. the BLBCs are shown as red horizontal bars on above or below the KSE $\mathrm{gains}_{\text {s }}$ and KSE $\mathrm{E}_{\text {losses }}$ respectively, and they are plotted as red overlays on the blue KSE curves. CNAs that occur more often the BLBCS vs. the BRCA7-mutated tumors are shown as green horizontal bars above or below the KSE gains $_{\text {and }}$ KSE $E_{\text {losses }}$ respectively, and as green overlays on the gray KSE curves. b: BRCA1-mutated tumors (blue) vs. luminal tumors (gray) c: BLBCs (blue) vs. luminal (gray) tumors. d: Luminal-J tumors (blue) vs. luminal-H tumors (gray). 
Table 2 Overlapping gains and losses that differentiate BLBCs and BRCA1-mutated tumors from luminal breast tumors

\begin{tabular}{|c|c|c|c|c|c|}
\hline $\mathrm{a}$ & Chr - region & Start (Mb) & End $(\mathrm{Mb})$ & peaks (Mb) BRCA1-related & peaks (Mb) BLBC \\
\hline \multirow[t]{19}{*}{ Gains } & $1 p$ & 58.05 & 65.50 & 62.00 & 61.20 \\
\hline & $2 p-1$ & 23.35 & 25.95 & 26.45 & 27.45 \\
\hline & $2 p-2$ & 56.80 & 65.20 & 60.85 & 63.95 \\
\hline & $3 q-1$ & 151.00 & 161.10 & 150.85 & 154.85 \\
\hline & $3 q-2$ & 175.80 & 186.40 & 178.55 & 179.80 \\
\hline & $6 p-1$ & 4.30 & 29.75 & $10.90,19.20$ & 14.05 \\
\hline & $6 p-2$ & 37.05 & 58.65 & $42.60,53.85$ & 36.65 \\
\hline & $6 q-1$ & 90.35 & 90.75 & 86.50 & 91.00 \\
\hline & $6 q-2$ & 105.20 & 112.30 & 107.15 & 107.75 \\
\hline & $6 q-3$ & 115.00 & 120.40 & no peak in region & \\
\hline & $6 q-4$ & 123.55 & 138.75 & 125.55 & 135.60 \\
\hline & $7 q-1$ & 132.80 & 139.40 & 134.40 & 130.25 \\
\hline & $7 q-2$ & 155.15 & 157.65 & 156.95 & 157.65 \\
\hline & $8 q$ & 127.40 & 132.95 & 120.95 & $121.95,135.3$ \\
\hline & $10 p-1$ & 1.30 & 12.45 & 5.10 & 6.45 \\
\hline & $10 p-2$ & 25.65 & 30.70 & 24.90 & 29.20 \\
\hline & $12 p$ & 0.25 & 11.60 & $0.25,16.10$ & 0.25 \\
\hline & $13 q$ & 101.25 & 107.00 & 99.55 & 110.35 \\
\hline & $19 q$ & 36.50 & 41.75 & 39.15 & 41.10 \\
\hline \multirow[t]{11}{*}{ Losses } & $3 p$ & 53.00 & 53.25 & 53.85 & 62.55 \\
\hline & $4 p$ & 15.65 & 27.05 & 18.55 & $11.00,26.65$ \\
\hline & $5 q-1$ & 50.05 & 146.95 & $57.70,70.75,89.75,102.30,116.25,133.80$ & $70.05,89.85,108.60,118.55,136.30$ \\
\hline & $5 q-2$ & 161.40 & 171.20 & $161.05,178.30$ & 157.30 \\
\hline & $10 q-1$ & 80.65 & 95.50 & $83.30,90.15$ & 91.05 \\
\hline & $10 q-2$ & 105.55 & 111.35 & 109.70 & 108.60 \\
\hline & $12 q-1$ & 47.70 & 48.35 & no peak in region & 42.15 \\
\hline & $12 q-2$ & 54.30 & 59.25 & 55.25 & 58.40 \\
\hline & $14 q-1$ & 38.30 & 44.75 & 40.65 & 36.35 \\
\hline & $14 q-2$ & 48.35 & 92.95 & $57.35,79.90,98.00$ & $55.20,66.15,81.0,95.05$ \\
\hline & $15 q$ & 35.10 & 49.65 & 44.40 & $33.70,42.85$ \\
\hline b & Chr - region & Start (Mb) & End (Mb) & peaks $(\mathrm{Mb})$ & \\
\hline \multirow[t]{3}{*}{ Gains } & $1 q$ & 176.70 & 215.40 & $177.35,202.75$ & \\
\hline & $8 p$ & 35.95 & 38.90 & 41.5 & \\
\hline & $16 \mathrm{p}$ & 4.30 & 27.75 & 15.8 & \\
\hline \multirow[t]{6}{*}{ Losses } & $6 q-1$ & 79.05 & 87.25 & 82.35 & \\
\hline & $6 q-2$ & 142.75 & 149.25 & no peak in region & \\
\hline & $6 q-3$ & 156.90 & 157.85 & 160.05 & \\
\hline & $11 q$ & 104.45 & 125.35 & $112.30,126.60$ & \\
\hline & $13 q$ & 91.70 & 95.50 & 99.1 & \\
\hline & $16 q$ & 45.15 & 88.50 & $52.30,79.40$ & \\
\hline
\end{tabular}

Table 2: a. Overlapping differential CNAs of BLBCs and BRCA1-mutated breast tumors vs luminal breast tumors. b. Overlapping differential CNAs of luminal breast tumors vs BRCA1-mutated breast tumors and BLBCs.

Differential gains and losses determined by comparative-KC-SMART (Figure 1b-c). a) Overlapping regions that differentiate BRCA1-mutated tumors and BLBCs from luminal tumors. b) overlapping regions that differentiate luminal-J and luminal-H tumors from BLBC/BRCA1-mutated tumors. KSE peak locations are listed for all tumor groups; peaks in italics fall just outside the region of overlap.

luminal tumor groups contained overlapping gains on chromosomes 1q, 8p and 16p, and an overlapping loss on chromosome 6q, 11q, 13q and 16q (Table 2).

Clearly, the differentially occurring CNAs detected by comparative-KC-SMART are fully dependent on the tumors included in the groups. However, when peaks of recurrent aberrations of two different analyses map closely together, this could point to a region whose gain or loss is relevant for tumorigenesis. Cancer-related genes that map to overlapping differential gains or losses between BRCA1-mutated tumors and BLBCs vs. luminal tumors are shown in Additional File 6. 


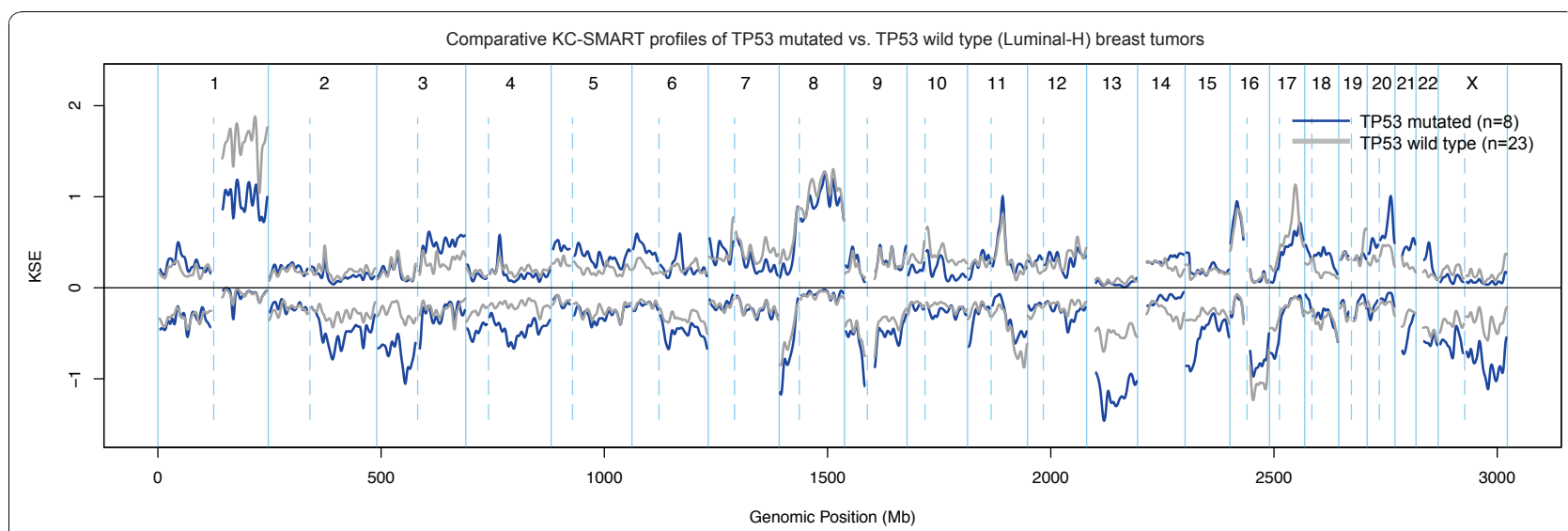

Figure 3 Comparative-KC-SMART analysis of aCGH data from luminal breast tumors. The luminal-H tumor group was divided into 8 TP53mutated tumors and 23 TP53 wild-type tumors. KSE curves of the TP53-mutated tumors (blue) and the TP53 wild-type tumors (gray) are shown for gains and losses separately. Comparative-KC-SMART analysis did not detect significant differences between the two tumor groups.

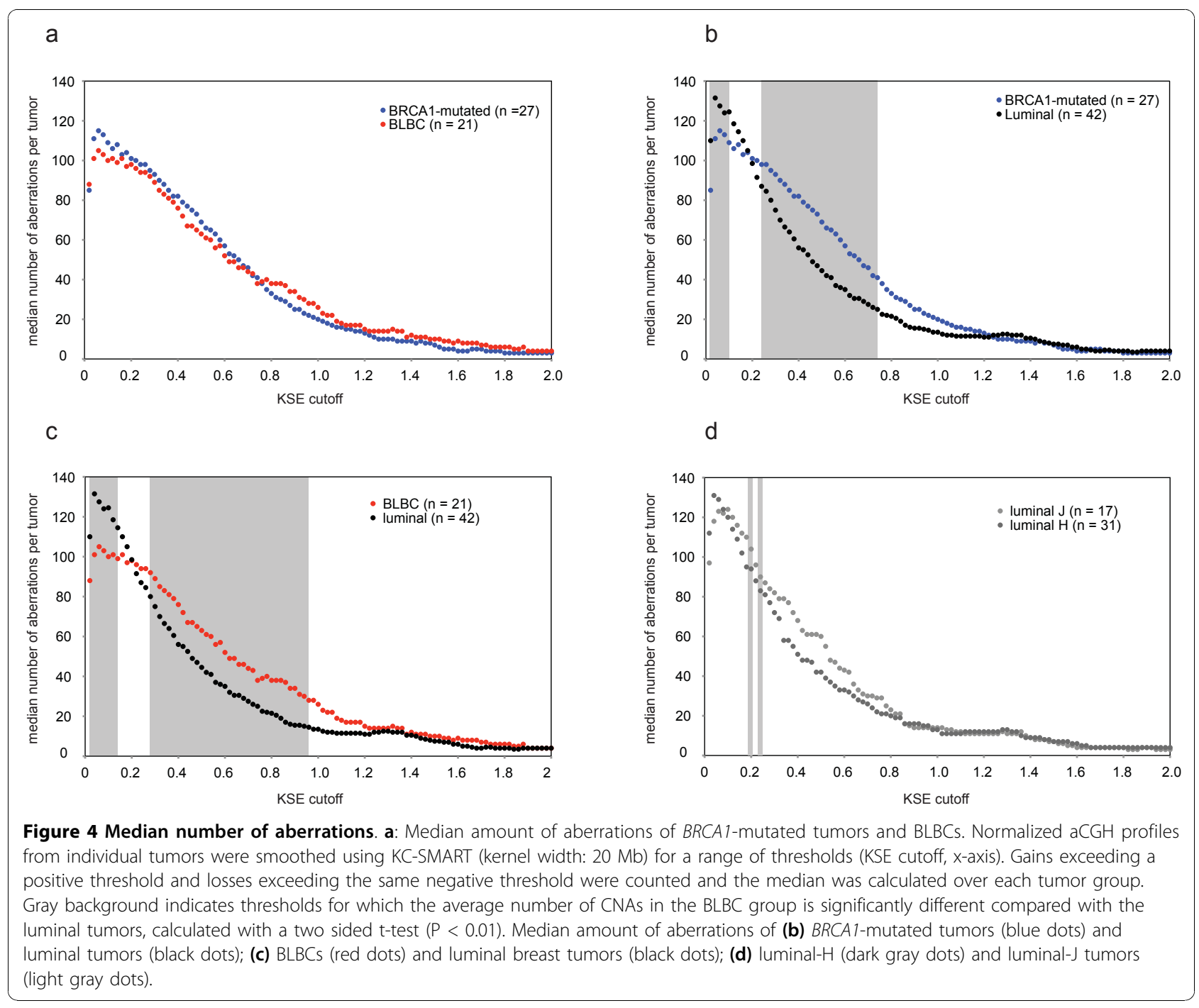




\section{Unsupervised hierarchical clustering of breast cancers}

The overlapping differential gains and losses of BLBCs and $B R C A 1$-mutated tumors may represent regions that discriminate BRCA1-mutated tumors and BLBCs from luminal tumors. To test this possibility, we performed an unsupervised hierarchical clustering analysis. First, we smoothed each tumor profile with KC-SMART to remove experimental noise. Then, for each of the regional aberrations specific for the BLBC/BRCA1-mutated tumors or the luminal tumors (shown in Table 2), we calculated the mean of all KSE values within the region for all tumors. We used the mean KSE values to perform a hierarchical clustering of samples and regions using complete linkage and pearson correlation (Figure 5). The tumors clustered in two branches: 6 luminal tumors and 47 of the $48 \mathrm{BLBCs} / B R C A 1$-mutated tumors clustered in one branch, whereas $1 B R C A 1$-mutated tumor and 42 of the 48 luminal- $\mathrm{H} / \mathrm{J}$ tumors clustered in the other branch. Interestingly, the BRCA1 and BLBC cases do not form separate clusters but mix together, meaning that a limited amount of regions can distinguish BLBCs and BRCA1mutated tumors from luminal tumors. The fact that the luminal-H and luminal-J tumors are mixed, shows that no unwanted biases are introduced by differences in quality of DNA from FFPE vs. fresh-frozen tumor material. As an additional internal control we have used the 6 luminal tumors for which DNA from FFPE and fresh- frozen tumor tissue was both available, and each of the 6 pairs cluster together. Notably, four of the six TP53 wildtype tumors that clustered within the BLBC/BRCA1mutated branch were luminal. One of the six luminal tumors that clustered within the BLBC/BRCA1-mutated branch also had a complex TP53 mutation, whereas only two of the luminal tumors clustering in the luminal branch had a complex TP53 mutation.

\section{Discussion}

BLBC is an aggressive subgroup of breast cancers for which, so far, no druggable target has been identified. In recent years it has become clear that phenotypic features of a subset of BLBCs resemble those of hereditary BRCA1-mutated breast cancers [13] and are distinctly different from the more common luminal breast tumors. BRCA1-mutated breast tumors are HR deficient (HRD) and can therefore be targeted with DNA-damaging agents or PARP inhibitors [38,39]. Because there is evidence that a substantial fraction of BLBCs have HR pathway defects [40], we set out to determine which molecular characteristics of BRCA1-mutated tumors are common to BLBCs but not to luminal tumors. Since some of these characteristics are likely to be linked to BRCA1-disfunction or the HRD phenotype, they might provide important leads for discovery of new biomarkers or drug targets.

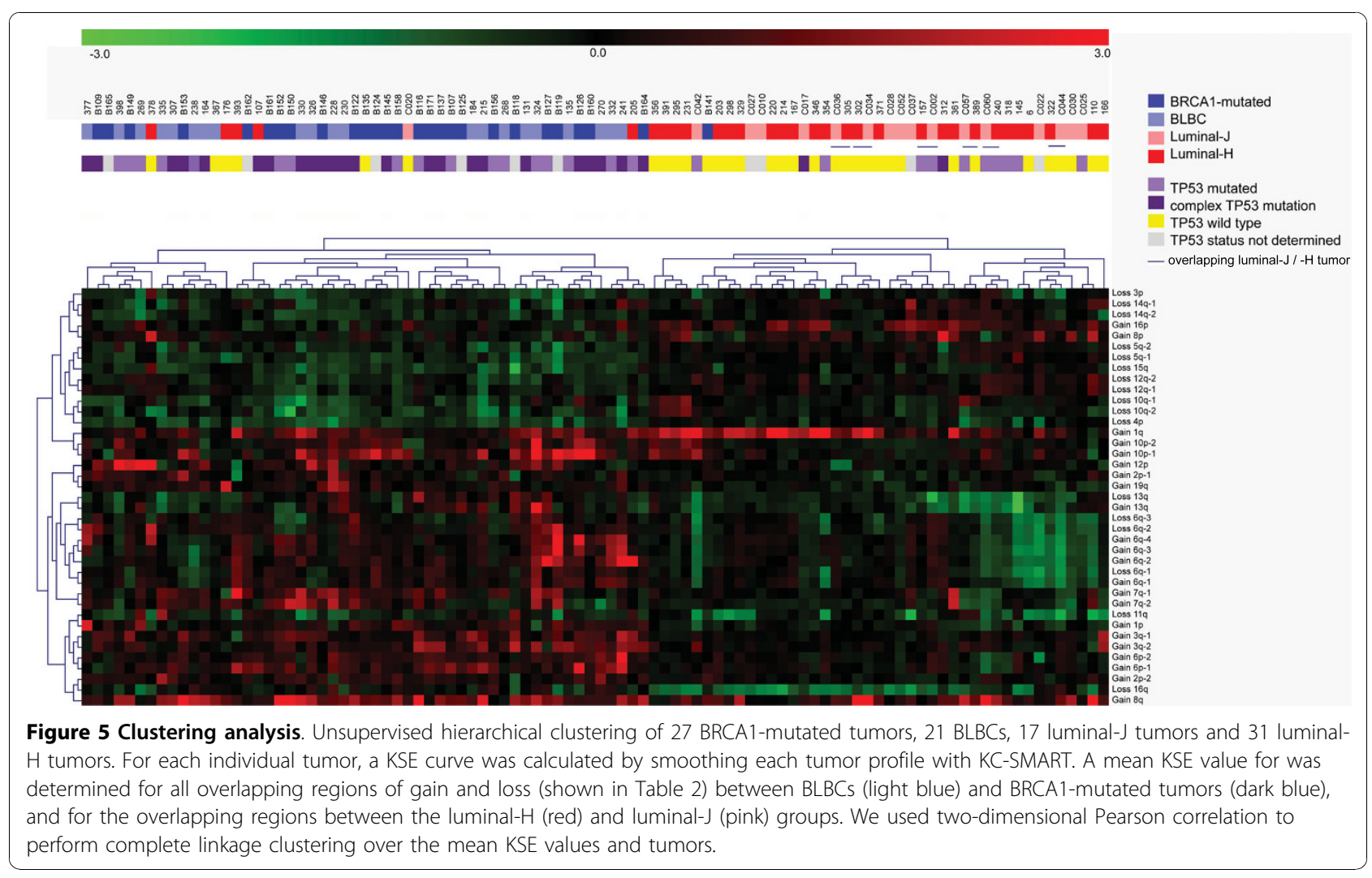




\section{High incidence of protein truncating TP53 mutations in BLBC and BRCA1-mutated breast cancer}

We and others have previously shown that BRCA1mutated breast tumors exhibit an increased frequency of TP53 mutations due to a selective increase in complex TP53 mutations such as frameshift, nonsense and splice mutations or in-frame insertions/deletions $[10,23]$. In this study, we found that almost all BRCA1mutated tumors and BLBCs are TP53 mutated compared with $25-50 \%$ of the luminal-tumors. Interestingly, $52.4 \%$ of the BRCA1-mutated breast tumors and $57.1 \%$ of the BLBCs have complex TP53 mutations, significantly more compared with $\sim 7 \%$ luminal tumors. It has been suggested that the increased incidence of complex TP53 mutations in BRCA1-mutated tumors is a direct consequence of the genomic instability resulting from the DNA repair defect induced by BRCA1 loss $[10,23]$. Furthermore, the DSB repair defect of BRCA1-deficient tumors might confer strong selection pressure on mutation of TP53 in order to abrogate the p53-dependent DNA damage checkpoint [41]. The high frequency of TP53 mutations in non-hereditary BLBCs might suggest that these tumors are also compromised in homology-directed DSB repair. To test this possibility, it would be interesting to perform functional assays to measure DNA damage response and DNA repair in non-hereditary BLBCs with a (complex) TP53 mutation. It has previously been suggested that TP53 mutations, including complex TP53 mutations, affecting the DNA binding domain of the p53 protein may cause resistance to several different cytotoxic compounds such as anthracyclins, $5 \mathrm{FU}$ and mitomycin $[42,43]$. However, tumors used in these studies were primarily invasive ductal carcinomas, most of which are likely not compromised in homology directed DSB repair. It is therefore interesting that Silver et al. recently reported a significant association between truncating TP53 mutations and cisplatin response in TNBCs [44].

It is interesting that, like us, Manie et al., found an increased frequency of complex TP53 mutations in $B R C A 1$-mutated breast tumors; however, they did not detect this feature in BLBCs $[10,23]$. It is possible that BLBCs are more effectively identified by gene expression profiling than by immunohistochemical selection of tumors negative for ER/PR/HER2 and positive for CK5/ 6, CK14 or EGFR, as done by Manie et al. Of note, the TP53 mutation analyses for the BRCA1-mutated breast tumors and the BLBCs described in this manuscript were performed in different labs, thereby reducing the possibility that the detection of a high incidence of complex/truncating TP53 mutations is due to a methodical artifact.

\section{Recurrent CNAs in luminal tumors}

Luminal breast tumors are mostly TP53 wild type, or they have a common TP53 hotspot mutation. Interestingly, the chromosome 1q gain and 16q loss (1q/16q) differentiate luminal tumors from BRCA1-mutated/ BLBC tumors. Co-occurrence of these aberrations results from an unbalanced translocation event $[45,46]$ and has been associated with TP53 wild-type status, low tumor grade and good prognosis [47]. Indeed, many of the ER-positive luminal tumors show the $1 \mathrm{q} / 16 \mathrm{q}$ cooccurrence. The peak of the chromosome 1q gain of the luminal tumor group maps to $202.75 \mathrm{Mb}$, with the $M D M 4$ gene at $(202.81 \mathrm{Mb})$, which is a negative regulator of p53 [48]. The 16q loss has two peaks, the first maps near the bromodomain 7 (BRD7) gene, associated with downregulation of p53 [49], CYLD, loss of which is associated with oncogenesis by activation of NF-KB signaling [50], and the retinoblastoma-like 2 gene (RBL2/ $p 130$ ), involved in $\mathrm{G}_{1} \mathrm{~S}$ cell cycle control and senescence [51]. The second peak on the 16q loss maps to one of the most active common fragile sites in the human genome, FRA16 D (associated with the WWOX gene), which could underlie the translocation process [52]. Together, these data suggest that, whereas development of BLBCs or BRCA1-mutated tumors depends on TP53 mutation, indirect p53 downregulation may be sufficient for luminal tumor development.

\section{aCGH profiles of BRCA1-mutated breast tumors resemble BLBCs}

$B R C A 1$-mutated breast tumors are associated with a specific aCGH profile which exhibits features that can be used to identify hereditary breast tumors for which information on BRCA1-mutation is not available $[19,22,24]$. Several previous studies have reported a specific aCGH profile for BLBCs different from other breast cancer subtypes [53,54]. Interestingly, comparison of CNAs from BRCA1-mutated tumors and BLBCs using comparative-KC-SMART yielded a limited set BRCA1- or BLBC-specific aberrations. The peaks of most gains and losses of BRCA1-mutated tumors and BLBCs co-localized, suggesting a common selection pressure during development of these tumors. Indeed, we found that BRCA1-mutated tumors and BLBCs showed many overlapping CNAs, including the chromosome 3q gain and the chromosome 5q loss. Importantly, clustering on the basis of these regions separated BLBCs and BRCA1-mutated breast tumors from luminal breast tumors.

\section{BRCA1 and TP53 involvement in the BLBC phenotype}

Our data show that BRCA1-mutated tumors share molecular characteristics of undifferentiated BLBCs. It has 
previously been proposed that $B R C A 1$-mutation is associated with BLBC because BRCA1 function has stem cell regulation properties and because loss of BRCA1 impairs DNA damage repair during epithelial cell differentiation [55]. However, it is also possible that a defect in DNA repair mechanisms is primarily harmful in proliferating cells, which are more prone to acquire genetic lesions during cell division. Notably, proliferating cells in the premenopausal mammary gland have been shown to rarely express hormone receptors whereas hormone receptor-positive cells only rarely divide [56]. In line with this, and in contrast to most breast tumors, both $B R C A 1$-mutated tumors and BLBCs often occur in premenopausal breast epithelia [57]. Therefore, we propose that inadequate DNA repair mechanisms result in increased susceptibility to genomic instability in the proliferating hormone receptor-negative cells of the premenopausal mammary gland. Furthermore, we propose that because of this, hormone receptor-negative cells depend heavily on p53-mediated cell cycle arrest and apoptosis to remain untransformed. This line of thought lends great importance to TP53 mutation in TNBC.

\section{Conclusions}

Our data suggest that a small subset of genomic regions may be useful for the identification of BRCA1-like BLBCs, which exhibit a high frequency of TP53 mutations, especially protein truncating mutations. These features of basal-like breast cancers might be useful for the identification of tumors with increased sensitivity to (high-dose or dose-dense) alkylating agents and PARP inhibitors. In support of this, it was recently reported that TP53 mutations in non-inflammatory BLBCs are highly predictive of complete response to dose-dense neoadjuvant chemotherapy with epirubicine-cyclophosphamide [58]. Furthermore, a significant positive correlation was found between truncating TP53 mutations and cisplatin response in TNBCs [44]. Together, these and our data support further investigation of (protein truncating) TP53 mutation status as a potential predictor of chemotherapy responsiveness in solid tumors.

\section{Additional material}

Additional file 1: fresh frozen tissue vs. FFPE. When comparing the aCGH profiles acquired by hybridization of DNA isolated from formalin fixed paraffin embedded tissue (FFPE) and fresh-frozen tissues we noticed that the log2 ratios obtained from the different DNA sources have different distributions. Therefore, we transformed both the FFPE and the fresh frozen datasets to have a mean of zero and a standard deviation of one, using all tumors (both luminal and basal-like) from the Horlings dataset, and all tumors (both BRCA1-mutated and luminal) from the Joosse dataset. The influence of this transformation is shown for the six tumors that were included in the aCGH datasets from both the luminal-H, and luminal-J tumor groups, hybridized from DNA isolated from fresh frozen tissue and FFPE material respectively. For each tumor, we compared the log2 ratios from both platforms. Red line: $\mathrm{x}=\mathrm{y}$ (if $\log 2$ ratios of FFPE and fresh frozen tumor data would be equal), Blue line: ratio of the factors used to scale both datasets to a standard deviation of 1.

Additional file 2: Frequency of TP53 mutations in BRCA1-mutated tumors and BLBCs. TP53 exons 2-9 were sequenced for 21/27 of the BRCA1-mutated tumors and for $13 / 21$ of the luminal-J tumors. TP53 exons 2-11 were sequenced for all BLBCs and luminal-H tumors (for TP53 mutation data, see Table 1).

Additional file 3: Regions of differential gains and losses detected by comparative-KC-SMART analyses between the BRCA1-mutated tumors and BLBCs. Genes that map within these regions and locations of the KSE peaks.

Additional file 4: Regions of differential gains and losses detected by comparative-KC-SMART analyses in (a) the BRCA1-mutated tumors and BLBCs vs. luminal tumors, genes in overlapping regions are shown in green. KSE peak locations are given for both tumor groups (b) luminal tumors vs. BRCA1-mutated and BLBC tumor groups, KSE peak locations are given for both tumor groups.

Additional file 5: Line plots. Normalized aCGH profiles of each individual tumor were smoothed with KC-SMART. Normalization was done by transformation of the log2 ratios from the FFPE aCGH dataset (i. e. all log2 ratios from BRCA1-mutated and luminal-J tumors taken together) and the fresh frozen dataset (see Methods section). The position of gains and exceeding the standard deviation of 1 are shown in red, the position of losses exceeding the standard deviation of -1 are shown in blue.

Additional file 6: Cancer related genes in overlapping gains and losses found by comparative-KC-SMART. Cancer-related genes that map to the differential gains and losses determined by comparative-KCSMART (Figure 2b/c). a) Cancer related genes that map in the overlapping regions that differentiate BRCA7-mutated and BLBC tumors from luminal tumors. b) Cancer related genes that map in the overlapping regions that differentiate luminal tumors from BLBC/BRCA1mutated tumors. KSE peak locations are listed for all tumor groups, peaks in italics fall just outside the region of overlap. Cancer related genes are taken from the Atlas of Genetics and Cytogenetics in Oncology and Haematology [59] and the cancer gene census [60]. The cancer related genes closest to the KSE peak locations are shown in red for the BRCA7mutated tumors, and in blue for the BLBCs tumors. When the same gene maps closest the peaks of both KSE-curves it is shown in green. For the luminal tumor group, cancer related genes closest to the KSE peak locations are shown in bold.

\section{Acknowledgements}

This work was supported by grants from the Dutch Cancer Society (NKI 2002-2635), the Netherlands Organization for Scientific Research (NWO Vidi 917.036.347) and the Susan G. Komen Breast Cancer Foundation (BCTR0403230). The authors thank Dr. Sabine Linn for sharing her expert view on this subject and Dr. Piet Borst and Dr. Hein te Riele for critically reading this manuscript.

\section{Author details}

'Division of Molecular Biology, Netherlands Cancer Institute, Plesmanlaan 121, 1066 CX Amsterdam, The Netherlands. ${ }^{2}$ Department of Pathology, Netherlands Cancer Institute, Plesmanlaan 121, 1066 CX Amsterdam, The Netherlands. ${ }^{3}$ Central Microarray Facility, Netherlands Cancer Institute, Plesmanlaan 121, 1066 CX Amsterdam, The Netherlands. ${ }^{4}$ Department of Genetics, Institute for Cancer Research, Norwegian Radium Hospital, Oslo University Hospital, Montebello, NO-0310 Oslo, Norway. ${ }^{5}$ Department of Pathology, Academic Medical Center, Meibergdreef 9, 1105 AZ Amsterdam, the Netherlands.

\section{Authors' contributions}

$\mathrm{HH}$ (first author) designed, performed the analyses and wrote the manuscript, $\mathrm{HH}$ (second author) and MJV provided tumor information of the Horlings tumor panel [25]. AV provided help with statistical analyses and 
performed the bioinformatics. AL and ALB-D sequenced TP53 from the tumor panel described by Horlings et al [25] and helped with TP53 mutation interpretation, PN provided tumor information from the Joosse tumor panel [24]. JJ supervised the project. All authors read and approved the manuscript.

\section{Competing interests}

The authors declare that they have no competing interests.

Received: 22 April 2010 Accepted: 30 November 2010

Published: 30 November 2010

\section{References}

1. Sims AH, Howell A, Howell SJ, Clarke RB: Origins of breast cancer subtypes and therapeutic implications. Nat Clin Pract Oncol 2007, 4:516-525.

2. Sorlie T, Perou CM, Tibshirani R, Aas T, Geisler S, Johnsen H, Hastie T, Eisen $M B$, van de Rijn $M$, Jeffrey SS, et al: Gene expression patterns of breast carcinomas distinguish tumor subclasses with clinical implications. Proc Natl Acad Sci USA 2001, 98:10869-10874.

3. Perou CM, Sorlie T, Eisen MB, van de Rijn M, Jeffrey SS, Rees CA, Pollack JR, Ross DT, Johnsen $H$, Akslen LA, et al: Molecular portraits of human breast tumours. Nature 2000, 406:747-752

4. Harris L, Fritsche H, Mennel R, Norton L, Ravdin P, Taube S, Somerfield MR, Hayes DF, Bast RC Jr: American Society of Clinical Oncology 2007 update of recommendations for the use of tumor markers in breast cancer. $J$ Clin Oncol 2007, 25:5287-5312.

5. Chu KC, Anderson WF, Fritz A, Ries LA, Brawley OW: Frequency distributions of breast cancer characteristics classified by estrogen receptor and progesterone receptor status for eight racial/ethnic groups. Cancer 2001, 92:37-45.

6. Effects of chemotherapy and hormonal therapy for early breast cancer on recurrence and 15-year survival: an overview of the randomised trials. Lancet 2005, 365:1687-1717.

7. Smith I, Procter M, Gelber RD, Guillaume S, Feyereislova A, Dowsett M, Goldhirsch A, Untch M, Mariani G, Baselga J, et al: 2-year follow-up of trastuzumab after adjuvant chemotherapy in HER2positive breast cancer: a randomised controlled trial. Lancet 2007 369:29-36.

8. Schneider BP, Winer EP, Foulkes WD, Garber J, Perou CM, Richardson A, Sledge GW, Carey LA: Triple-negative breast cancer: risk factors to potential targets. Clin Cancer Res 2008, 14:8010-8018.

9. Linn SC, Van 't Veer $\mathrm{LJ}$ : Clinical relevance of the triple-negative breast cancer concept: Genetic basis and clinical utility of the concept. European journal of cancer (Oxford, England: 1990) 2009, 45:11-26.

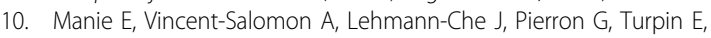
Warcoin M, Gruel N, Lebigot I, Sastre-Garau X, Lidereau R, et al: High frequency of TP53 mutation in BRCA1 and sporadic basal-like carcinomas but not in BRCA1 luminal breast tumors. Cancer Res 2009, 69:663-671.

11. Langerod $A$, Zhao $H$, Borgan $O$, Nesland JM, Bukholm IR, Ikdahl T, Karesen R, Borresen-Dale AL, Jeffrey SS: TP53 mutation status and gene expression profiles are powerful prognostic markers of breast cancer. Breast Cancer Res 2007, 9:R30.

12. Lakhani SR, Reis-Filho JS, Fulford L, Penault-Llorca F, van der Vijver M, Parry S, Bishop T, Benitez J, Rivas C, Bignon YJ, et al: Prediction of BRCA1 status in patients with breast cancer using estrogen receptor and basal phenotype. Clin Cancer Res 2005, 11:5175-5180.

13. Turner NC, Reis-Filho JS: Basal-like breast cancer and the BRCA1 phenotype. Oncogene 2006, 25:5846-5853.

14. Turner N, Tutt A, Ashworth A: Hallmarks of 'BRCAness' in sporadic cancers. Nat Rev Cancer 2004, 4:814-819.

15. Fong PC, Boss DS, Yap TA, Tutt A, Wu P, Mergui-Roelvink M, Mortimer $P$, Swaisland H, Lau A, O'Connor MJ, et al: Inhibition of poly(ADP-ribose) polymerase in tumors from BRCA mutation carriers. N Engl J Med 2009, 361:123-134.

16. Byrski T, Huzarski T, Dent R, Gronwald J, Zuziak D, Cybulski C, Kladny J, Gorski B, Lubinski J, Narod SA: Response to neoadjuvant therapy with cisplatin in BRCA1-positive breast cancer patients. Breast Cancer Res Treat 2009, 115:359-363.
17. Kennedy RD, Quinn JE, Mullan PB, Johnston PG, Harkin DP: The role of BRCA1 in the cellular response to chemotherapy. J Natl Cancer Inst 2004, 96:1659-1668.

18. Moynahan ME, Cui TY, Jasin M: Homology-directed dna repair, mitomycin-c resistance, and chromosome stability is restored with correction of a Brca1 mutation. Cancer Res 2001, 61:4842-4850.

19. van Beers EH, van Welsem T, Wessels LF, Li Y, Oldenburg RA, Devilee $P$, Cornelisse CJ, Verhoef S, Hogervorst FB, van't Veer LJ, Nederlof PM: Comparative genomic hybridization profiles in human BRCA1 and BRCA2 breast tumors highlight differential sets of genomic aberrations. Cancer Res 2005, 65:822-827.

20. Tirkkonen M, Johannsson O, Agnarsson BA, Olsson H, Ingvarsson S, Karhu R, Tanner M, Isola J, Barkardottir RB, Borg A, Kallioniemi OP: Distinct somatic genetic changes associated with tumor progression in carriers of BRCA1 and BRCA2 germ-line mutations. Cancer Res 1997, 57:1222-1227.

21. Jonsson G, Naylor TL, Vallon-Christersson J, Staaf J, Huang J, Ward MR, Greshock JD, Luts L, Olsson H, Rahman N, et al: Distinct genomic profiles in hereditary breast tumors identified by array-based comparative genomic hybridization. Cancer Res 2005, 65:7612-7621

22. Wessels LF, van Welsem T, Hart AA, van't Veer $L$, Reinders MJ, Nederlof PM: Molecular classification of breast carcinomas by comparative genomic hybridization: a specific somatic genetic profile for BRCA1 tumors. Cancer Res 2002, 62:7110-7117.

23. Holstege $H$, Joosse SA, van Oostrom CT, Nederlof PM, de Vries A, Jonkers J: High incidence of protein-truncating TP53 mutations in BRCA1-related breast cancer. Cancer Res 2009, 69:3625-3633.

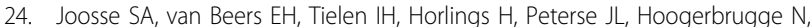
Ligtenberg MJ, Wessels LF, Axwijk P, Verhoef $S$, et al: Prediction of BRCA1association in hereditary non-BRCA1/2 breast carcinomas with arrayCGH. Breast Cancer Res Treat 2009, 116:479-489.

25. Horlings HM, Lai C, Nuyten DS, Halfwerk H, Kristel P, van Beers E, Joosse SA, Klijn C, Nederlof PM, Reinders MJ, et al: Integration of DNA copy number alterations and prognostic gene expression signatures in breast cancer patients. Clin Cancer Res 2010, 16:651-663.

26. van de Vijver MJ, He YD, van't Veer LJ, Dai H, Hart AA, Voskuil DW, Schreiber GJ, Peterse JL, Roberts C, Marton MJ, et al: A gene-expression signature as a predictor of survival in breast cancer. N Engl J Med 2002, 347:1999-2009.

27. Ng PC, Henikoff S: Predicting deleterious amino acid substitutions. Genome Res 2001, 11:863-874.

28. SIFT Database: Sorting Intolerant From Tolerant. [http://blocks.fhcrc.org/ sift/SIFT.html].

29. Petitjean A, Mathe E, Kato S, Ishioka C, Tavtigian SV, Hainaut P, Olivier M: Impact of mutant p53 functional properties on TP53 mutation patterns and tumor phenotype: lessons from recent developments in the IARC TP53 database. Hum Mutat 2007, 28:622-629.

30. IARC TP53 Database. [http://www-p53.iarc.fr].

31. Olivier M, Langerod A, Carrieri P, Bergh J, Klaar S, Eyfjord J, Theillet C, Rodriguez C, Lidereau R, Bieche I, et al: The clinical value of somatic TP53 gene mutations in 1,794 patients with breast cancer. Clin Cancer Res 2006, 12:1157-1167.

32. Walker DR, Bond JP, Tarone RE, Harris CC, Makalowski W, Boguski MS, Greenblatt MS: Evolutionary conservation and somatic mutation hotspot maps of p53: correlation with p53 protein structural and functional features. Oncogene 1999, 18:211-218.

33. Joosse SA, van Beers EH, Nederlof PM: Automated array-CGH optimized for archival formalin-fixed, paraffin-embedded tumor material. BMC Cancer 2007, 7:43.

34. Klijn C, Holstege H, de Ridder J, Liu X, Reinders M, Jonkers J, Wessels L: Identification of cancer genes using a statistical framework for multiexperiment analysis of nondiscretized array CGH data. Nucleic Acids Res 2008, 36:e13.

35. Holstege $H$, van Beers $E$, Velds $A$, Liu $X$, Joosse $S A$, Klarenbeek $S$, Schut $E$, Kerkhoven R, Klijn CN, Wessels LF, et al: Cross-species comparison of aCGH data from mouse and human BRCA1- and BRCA2-mutated breast cancers. BMC Cancer 2010, 10:455.

36. Bioconductor. [http://www.bioconductor.org/packages/2.4/bioc/html/ KCsmart.html] 
37. Saeed Al, Bhagabati NK, Braisted JC, Liang W, Sharov V, Howe EA, Li J, Thiagarajan M, White JA, Quackenbush J: TM4 microarray software suite. Methods Enzymol 2006, 411:134-193.

38. Farmer H, McCabe N, Lord CJ, Tutt AN, Johnson DA, Richardson TB, Santarosa M, Dillon KJ, Hickson I, Knights C, et al: Targeting the DNA repair defect in BRCA mutant cells as a therapeutic strategy. Nature 2005, 434:917-921.

39. Ashworth A: A synthetic lethal therapeutic approach: poly(ADP) ribose polymerase inhibitors for the treatment of cancers deficient in DNA double-strand break repair. J Clin Oncol 2008, 26:3785-3790.

40. Han J, Haiman C, Niu T, Guo Q, Cox DG, Willett WC, Hankinson SE, Hunter DJ: Genetic variation in DNA repair pathway genes and premenopausal breast cancer risk. Breast Cancer Res Treat 2009, 115:613-622

41. Brugarolas J, Jacks T: Double indemnity: p53, BRCA and cancer. p53 mutation partially rescues developmental arrest in Brca1 and Brca2 null mice, suggesting a role for familial breast cancer genes in DNA damage repair. Nat Med 1997, 3:721-722.

42. Geisler S, Borresen-Dale AL, Johnsen H, Aas T, Geisler J, Akslen LA, Anker G, Lonning PE: TP53 gene mutations predict the response to neoadjuvant treatment with 5-fluorouracil and mitomycin in locally advanced breast cancer. Clin Cancer Res 2003, 9:5582-5588.

43. Geisler S, Lonning PE, Aas T, Johnsen H, Fluge O, Haugen DF, Lillehaug JR, Akslen LA, Borresen-Dale AL: Influence of TP53 gene alterations and cerbB-2 expression on the response to treatment with doxorubicin in locally advanced breast cancer. Cancer Res 2001, 61:2505-2512.

44. Silver DP, Richardson AL, Eklund AC, Wang ZC, Szallasi Z, Li Q, Juul N, Leong CO, Calogrias D, Buraimoh A, et al: Efficacy of Neoadjuvant Cisplatin in Triple-Negative Breast Cancer. J Clin Oncol .

45. Farabegoli F, Hermsen MA, Ceccarelli C, Santini D, Weiss MM, Meijer GA van Diest PJ: Simultaneous chromosome 1q gain and $16 \mathrm{q}$ loss is associated with steroid receptor presence and low proliferation in breast carcinoma. Mod Pathol 2004, 17:449-455.

46. Tsarouha H, Pandis N, Bardi G, Teixeira MR, Andersen JA, Heim S: Karyotypic evolution in breast carcinomas with i(1)(q10) and der(1;16) (q10;p10) as the primary chromosome abnormality. Cancer Genet Cytogenet 1999, 113:156-161.

47. Fridlyand J, Snijders AM, Ylstra B, Li H, Olshen A, Segraves R, Dairkee S, Tokuyasu T, Ljung BM, Jain AN, et al: Breast tumor copy number aberration phenotypes and genomic instability. BMC Cancer 2006, 6:96.

48. Toledo F, Krummel KA, Lee CJ, Liu CW, Rodewald LW, Tang M, Wahl GM: A mouse p53 mutant lacking the proline-rich domain rescues Mdm4 deficiency and provides insight into the Mdm2-Mdm4-p53 regulatory network. Cancer Cell 2006, 9:273-285.

49. Drost J, Mantovani F, Tocco F, Elkon R, Comel A, Holstege H, Kerkhoven R, Jonkers J, Voorhoeve PM, Agami R, Del Sal G: BRD7 is a candidate tumour suppressor gene required for p53 function. Nat Cell Biol 2010, 12:380-389.

50. Brummelkamp TR, Nijman SM, Dirac AM, Bernards R: Loss of the cylindromatosis tumour suppressor inhibits apoptosis by activating NFkappaB. Nature 2003, 424:797-801.

51. Helmbold H, Komm N, Deppert W, Bohn W: Rb2/p130 is the dominating pocket protein in the p53-p21 DNA damage response pathway leading to senescence. Oncogene 2009, 28:3456-3467.

52. Durkin SG, Glover TW: Chromosome fragile sites. Annu Rev Genet 2007, 41:169-192.

53. Bergamaschi A, Kim YH, Wang P, Sorlie T, Hernandez-Boussard T, Lonning PE, Tibshirani R, Borresen-Dale AL, Pollack JR: Distinct patterns of DNA copy number alteration are associated with different clinicopathological features and gene-expression subtypes of breast cancer. Genes Chromosomes Cancer 2006, 45:1033-1040.

54. Adelaide J, Finetti P, Bekhouche I, Repellini L, Geneix J, Sircoulomb F, Charafe-Jauffret E, Cervera N, Desplans J, Parzy D, et al: Integrated profiling of basal and luminal breast cancers. Cancer Res 2007, 67:11565-11575.

55. Foulkes WD: BRCA1 functions as a breast stem cell regulator. J Med Genet 2004, 41:1-5

56. Clarke RB, Howell A, Potten CS, Anderson E: Dissociation between steroid receptor expression and cell proliferation in the human breast. Cancer Res 1997, 57:4987-4991.

57. Young SR, Pilarski RT, Donenberg T, Shapiro C, Hammond LS, Miller J, Brooks KA, Cohen S, Tenenholz B, Desai D, et al: The prevalence of BRCA1 mutations among young women with triple-negative breast cancer. $B M C$ Cancer 2009, 9:86.

58. Bertheau P, Turpin E, Rickman DS, Espie M, de Reynies A, Feugeas JP, Plassa LF, Soliman H, Varna M, de Roquancourt A, et al: Exquisite sensitivity of TP53 mutant and basal breast cancers to a dose-dense epirubicincyclophosphamide regimen. PLoS Med 2007, 4:e90.

59. Huret $J$, Dessen P, Bernheim A: Atlas of Genetics and Cytogenetics in Oncology and Haematology, year 2003. Nucleic Acids Res 2003, 31:272-274.

60. Futreal PA, Coin L, Marshall M, Down T, Hubbard T, Wooster R, Rahman N, Stratton MR: A census of human cancer genes. Nat Rev Cancer 2004, 4:177-183.

\section{Pre-publication history}

The pre-publication history for this paper can be accessed here: http://www.biomedcentral.com/1471-2407/10/654/prepub

\section{doi:10.1186/1471-2407-10-654}

Cite this article as: Holstege et al:: BRCA1-mutated and basal-like breast cancers have similar aCGH profiles and a high incidence of protein truncating TP53 mutations. BMC Cancer 2010 10:654.

\section{Submit your next manuscript to BioMed Central and take full advantage of:}

- Convenient online submission

- Thorough peer review

- No space constraints or color figure charges

- Immediate publication on acceptance

- Inclusion in PubMed, CAS, Scopus and Google Scholar

- Research which is freely available for redistribution

Submit your manuscript at www.biomedcentral.com/submit
C Biomed Central 